\title{
THE GENETICS OF ALPHA-METHYL-GLUCOSIDE FERMENTATION IN SACCHAROMYCES
}

\author{
DONALD C. HAWTHORNE \\ Department of Microbiology, University of Washington, Seattle, Washington
}

\section{INTRODUCTION}

Received 3.x.57

IT has been established that in Saccharomyces the fermentation of a given sugar can be controlled by several genes. For example, for the fermentation of maltose and raffinose, four and three polymeric genes, respectively, have been demonstrated by Winge and Roberts (1952). For galactose fermentation, three complementary genes are known (Hawthorne, 1956). Since first reporting a single gene controlling alpha-methyl-glucoside fermentation, Lindegren (1949) has published data on the irregular segregations at this locus, attributing to "gene conversion" the ratios deviating from the $2: 2$ expected in tetrads from a hybrid heterozygous for a single gene (Lindegren, I953; and Lindegren and Lindegren, 1956). The work reported below indicates that a more complex genetic situation exists in our breeding stocks, in that at least five different genes can be demonstrated to be involved in the fermentation of alpha-methyl-glucoside.

\section{MATERIALS AND METHODS}

The parental haploid strains used in the crosses that follow were either obtained directly from Dr C. C. Lindegren (clones I 426A and 1428) or were derived from cultures originating in his laboratory. With two exceptions, the crosses were made either by pairing haploid cells (Chen, 1950) or by selecting prototrophic diploid clones from a mixture of auxotrophic haploid parents that had been plated on minimal medium (Pomper and Burkholder, 1949). In the two exceptions, crosses 4 and 8 , a mass mating of haploid cells was made as described by Lindegren and Lindegren (1943).

The sporulation procedure suggested by Lindegren (1949) was followed. Whenever it was feasible, only linear four-spored asci were dissected (Hawthorne, I955). Only asci in which all four spores survived were retained for genetic analysis. Since the hybrids were heterozygous for from five to ten genes in addition to the genes controlling alpha-methyl-glucoside fermentation, it was possible to recognise and eliminate from the analysis anomalous asci due to polyploidy (Roman, Hawthorne and Douglas, I95I) or post-meiotic nuclear fusion (Roman and Sands, I953 ; Winge and Roberts, 1954).

The tests for the fermentation of alpha-methyl-glucoside were made in Kahn tubes containing $\mathrm{I} \cdot 5$ c.c. of the following medium adjusted to $p \mathrm{H} 6 \cdot \mathrm{o}:$ I per cent. peptone, I per cent. yeast extract, I per cent. alpha-methyl-glucoside, and the indicator bromcresol purple. An alpha-methyl-glucoside fermenter grows vigorously in this medium and causes a change in the colour of the indicator due to acid production. The reliability of this testing procedure has been confirmed by duplicate tests using Durham fermentation tubes. 


\section{RESULTS \\ Evidence for the genes $M G_{1}$ and $M G_{2}$}

The first indication that more than one locus was involved in alpha-methyl-glucoside fermentation was obtained from the results. of crosses (table I) in which the haploid parents were non-fermenters. In all four cases, the diploid hybrids turned out to be fermenters and the asci obtained from them exhibited the $2: 2$, I $: 3$, and $0: 4$ segregations expected if two loci were involved. The distributions of these ratios among 35 asci, $9(2: 2), 2 \mathrm{I}(\mathrm{I}: 3)$, and $5(0: 4)$, suggested that the parental haploids differ in two genes, $M G_{1}$ and $M G_{2}$, both of which are needed for alpha-methyl-glucoside fermentation, and that the three ascus types have the following compositions.

$\begin{array}{lllllll}\text { Spore } a & M G_{1} M G_{2}(+) & M G_{1} M G_{2}(+) & M G_{1} m g_{2} & (-) \\ \text { Spore } b & M G_{1} M G_{2}(+) & M G_{1} m g_{2} & (-) & M G_{1} m g_{2} & (-) \\ \text { Spore } c & m g_{1} m g_{2} & (-) & m g_{1} M G_{2} & (-) & m g_{1} M G_{2} & (-) \\ \text { Spore } d & m g_{1} m g_{2} & (-) & m g_{1} m g_{2} & (-) & m g_{1} M G_{2} & (-)\end{array}$

The genotype of the common parent in the first three crosses, Ior I-I $a$, was designated $m g_{1} M G_{2}$. The other parents, IooI-I $7 a$, IOOI-8d, and IOOI-I $4 a$, were on this hypothesis $M G_{1} m g_{2}$. The negative segregants could be tested to determine if they were of the genotype $M G_{1} m g_{2}, m g_{1} M G_{2}$, or $m g_{1} m g_{2}$ by making crosses to the above haploid parents and then inoculating the mixture containing zygotes into the alpha-methyl-glucoside medium. If the zygotes give rise to fermenters, the haploid being tested is of the complementary genotype. In this way, the genotypes of the parents of the fourth cross were found to be $m g_{1} M G_{2}$ for $\mathrm{I} 33^{-1} b$ and $M G_{1} m g_{2}$ for 1428 .

In a series of crosses made to confirm the zygote test described above, non-fermenter segregants of each of the postulated genotypes were crossed with fermenter haploids. The hybrids in every case were fermenters. The crosses involving the genotypes $m g_{1} M G_{2}$ and $M G_{1} m g_{2}$ gave asci with $2: 2$ segregations as expected. Also as expected, the one cross involving the genotype $m g_{1} m g_{2}$ gave asci with two gene segregations, as shown in table 2 .

\section{Evidence for a third alpha-methyl-glucoside gene, $\mathrm{MG}_{3}$}

Two crosses involving non-fermenters of the genotype $M G_{1} m g_{2}$ and the same fermenter parent, roo3-6c, had been expected to give asci with only $2: 2$ segregations, reflecting the segregation of $M G_{2}$. Instead only 19 of the 32 asci of crosses II and I2 (table 3 ), gave $2: 2$ segregations and the remaining 13 asci showed $1: 3$ segregations for alpha-methyl-glucoside. These segregations suggested that still another gene was involved in the fermentation of alpha-methylglucoside. Additional evidence for the new gene was obtained from the results of a cross in which both haploid parents were non-fermenters. Of the 13 asci from cross 13 (table 3 ), there were 8 (2:2), 4 (1:3), 
TABLE I

Segregations for alpha-methyl-glucoside fermentation in asci from hybrids of the genotype $\mathrm{MG}_{1} \mathrm{mg}_{2} / \mathrm{mg}_{1} \mathrm{MG}_{2}$

\begin{tabular}{|c|c|c|c|c|c|}
\hline \multirow{2}{*}{ Cross } & \multirow{2}{*}{ Parents and phenotypes } & \multirow{2}{*}{$\begin{array}{l}\text { Hybrid and } \\
\text { phenotype }\end{array}$} & \multicolumn{3}{|c|}{ Number of asci segregating as } \\
\hline & & & $2+: 2-$ & $\mathrm{I}+: 3-$ & $0+: 4^{*}$ \\
\hline I & IOOI-I $7 a(-) \times$ IOII-I $a(-)$. & $\begin{array}{l}\text { I } 33, \text { I } 35(+) \\
\text { I } 36 \text { and I } 39\end{array}$ & 3 & IO & 2 \\
\hline 2 & $\operatorname{IOOI-8d}(-) \times \operatorname{IOII}-\mathrm{I} a(-)$ & $\begin{array}{l}\text { I } 42, \text { I } 43(+) \\
\text { I } 44 \text { and I } 45\end{array}$ & 3 & 8 & 2 \\
\hline 3 & IOOI-I $4 a(-) \times$ IOII-I $a(-)$. & $\operatorname{lol} 5(+)$ & 2 & I & I \\
\hline 4 & $1428(-) \times 133-1 b(-)$ & I0I $7(+)$ & I & 2 & o \\
\hline
\end{tabular}

* Fermenters $(+)$ : non-fermenters $(-)$.

\section{TABLE 2}

Segregations for alpha-methyl-glucoside fermentation in asci from hybrids of the following genolypes: $\mathrm{MG}_{1} \mathrm{MG}_{2} / \mathrm{mg}_{1} \mathrm{mg}_{2}$ in cross $5, \mathrm{MG}_{1} \mathrm{MG}_{2} / \mathrm{mg}_{1} \mathrm{MG}_{2}$ in crosses $6,7,8$ and $9, \mathrm{MG}_{1} \mathrm{MG}_{2} / \mathrm{MG}_{1} \mathrm{mg}_{2}$ in cross io

\begin{tabular}{|c|c|c|c|c|c|}
\hline \multirow{2}{*}{ Cross } & \multirow{2}{*}{ Parents and phenotypes } & \multirow{2}{*}{$\begin{array}{l}\text { Hybrid and } \\
\text { phenotype }\end{array}$} & \multicolumn{3}{|c|}{ Number of asci segregating as } \\
\hline & & & $2+: 2-$ & $\mathrm{I}+: 3-$ & $0+: 4^{*}$ \\
\hline 5 & I OI $7-2 d(+) \times 1005-2 d(-)$ & $\operatorname{101} 8(+)$ & 0 & 7 & 0 \\
\hline 6 & IOI $7-2 b(+) \times 1018-4 a(-)$ & $\operatorname{lol} 9(+)$ & 3 & o & 0 \\
\hline 7 & I $42-4 c(+) \times$ I OI $8-4 a(-)$ & $1036(+)$ & I3 & o & o \\
\hline 8 & $\operatorname{I0I} 9-\operatorname{I} d(+) \times \operatorname{I} 3^{6-1} b(-)$ & $1043(+)$ & 3 & o & o \\
\hline 9 & $1019-1 c(+) \times 1036-12 c(-)$ & $1047(+)$ & 4 & o & o \\
\hline IO & $1018-6 a(+) \times 1001-16 b(-)$ & $1033(+)$ & 6 & o & o \\
\hline
\end{tabular}

* Fermenters $(+)$ : non-fermenters $(-)$.

TABLE 3

Segregations for alpha-methyl-glucoside fermentation in asci from hybrids of the following genotypes: $\mathrm{mg}_{1} \mathrm{MG}_{2} \mathrm{MG}_{3} / \mathrm{MG}_{1} \mathrm{mg}_{2} \mathrm{mg}_{3}$ in crosses II and I2, $\mathrm{MG}_{1} \mathrm{mg}_{2} \mathrm{MG}_{3} / \mathrm{mg}_{1}$ $\mathrm{MG}_{2} \mathrm{mg}_{3}$ in cross 13

\begin{tabular}{|c|c|c|c|c|c|}
\hline \multirow{2}{*}{ Cross } & \multirow{2}{*}{ Parents and phenotypes } & \multirow{2}{*}{$\begin{array}{l}\text { Hybrid and } \\
\text { phenotype }\end{array}$} & \multicolumn{3}{|c|}{ Number of asci segregating as } \\
\hline & & & $2+: 2-$ & $1+: 3-$ & $0+: 4-*$ \\
\hline I I & I003-6c $(+) \times$ I 00 I- I $76(-)$ & $\begin{array}{c}1,2,5(+) \\
6 \text { and } 12\end{array}$ & I I & 9 & 0 \\
\hline I 2 & I $003-6 c(+) \times$ I OOI-I $4 a(-)$. & $\begin{array}{c}48,52(+) \\
\text { and } 84\end{array}$ & 8 & 4 & 0 \\
\hline 13 & I $29-3^{c}(-) \times 143-3 a(-)$ & I016 $6(t)$ & 8 & 4 & I \\
\hline
\end{tabular}

* Fermenters $(+)$ : non-fermenters (-). 
and I (o:4) segregations. One parent, I 43-3a, had been tested and found to be of the genotype $m g_{1} M G_{2}$; the other parent, I 29-3c, was presumed to be of the genotype $M G_{1} m g_{2}$. However, the preponderance of $2: 2$ segregations over the $1: 3$ and $0: 4$ segregations, as in the results of crosses I I and I2, could not be accounted for by any simple scheme involving only two genes $M G_{1}$ and $M G_{2}$. These results could be explained if it were assumed that there is a third gene, $M G_{3}$, which is equivalent to $M G_{1}$ in that a combination of the genes $M G_{2}$ and $M G_{3}$ will enable the yeast to ferment alpha-methyl-glucoside in the absence of $M G_{1}$. Thus the excess of $2: 2$ asci over $I: 3$ and $0: 4$ asci from cross i 3 would be expected if I 29-3c were $M G_{1} m g_{2} M G_{3}$,

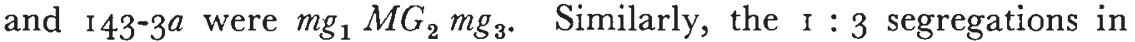
crosses I I and I 2 can be accounted for if the parents are of genotype

TABLE 4

Segregations for alpha-methyl-glucoside fermentation in asci from hybrids of the following genotypes: $\mathrm{mg}_{1} \mathrm{MG}_{2} \mathrm{MG}_{3} / \mathrm{mg}_{1} \mathrm{MG}_{2} \mathrm{mg}_{3}$ in crosses ${ }_{14}$ and ${ }_{15}, \mathrm{mg}_{1} \mathrm{MG}_{2} \mathrm{MG}_{3} / \mathrm{mg}_{1}$ $\mathrm{mg}_{2} \mathrm{mg}_{3}$ in cross $16, \mathrm{mg}_{1} \mathrm{MG}_{2} \mathrm{MG}_{3} / \mathrm{mg}_{1} \mathrm{mg}_{2} \mathrm{MG}_{3}$ in cross $17, \mathrm{MG}_{1} \mathrm{MG}_{2}$ $\mathrm{mg}_{3} / \mathrm{mg}_{1} \mathrm{MG}_{2} \mathrm{MG}_{3}$ in cross 18

\begin{tabular}{|c|c|c|c|c|c|c|c}
\hline Cross & Parents and phenotypes & $\begin{array}{c}\text { Hybrid and } \\
\text { phenotype }\end{array}$ & \multicolumn{3}{|c}{ Number of asci segregating as } \\
\cline { 3 - 7 } & & & $4+: 0-$ & $3+: 1-$ & $2+: 2-$ & $1+: 3-$ & $0+: 4-$ \\
\hline & & & & & & & \\
14 & $1003-6 c(+) \times 145-1 c(-)$ & $1035(+)$ & 0 & 0 & 21 & 0 & 0 \\
15 & $1035-6 c(+) \times 1036-2 c(-)$ & $1040(+)$ & 0 & 0 & 11 & 0 & 0 \\
16 & $1003-6 c(+) \times 133-3 a(-)$ & $1034(+)$ & 0 & 0 & 2 & 9 & 1 \\
17 & $1035-2 b(+) \times 1034-1 d(-)$ & $1037(+)$ & 0 & 0 & 9 & 0 & 0 \\
18 & $1036-7 a(+) \times 1040-7 b(+)$ & $1078(+)$ & 2 & 9 & 3 & 0 & 0 \\
\hline
\end{tabular}

* Fermenters $(+)$ : non-fermenters $(-)$.

$m g_{1} M G_{2} M G_{3}$ (I003-6c) and $M G_{1} m g_{2} m g_{3}$ (IOOI-I $7 b$ and IOOI-I $4 a$ ). If the three genes segregate independently and show no centromere linkage, a hybrid heterozygous for all three would give $2: 2$, I : 3 , and $0: 4$ segregations in the ratio of $19: 16: 1$. The actual segregations obtained for the 45 asci of crosses II, I 2, and I3, 27 (2:2), I 7 ( $: 3$ ), and I $(0: 4)$, do not differ significantly from the expected frequencies : $23.75(2: 2), 20(1: 3)$, and $1 \cdot 25(0: 4)$.

With this indication of a third alpha-methyl-glucoside gene, $M G_{3}$, the crosses reported in the previous section were re-examined. The results are consistent with the interpretation that the parental strains, IOOI-8d, IOOI-I $4 a$, IOOI-I $7 a$, IоII-I $a$, I 428 , and I005-2d, and consequently all segregants carried the recessive gene $m g_{3}$.

For further evidence of the correctness of the above explanation, the following crosses were made. The fermenter presumed to be $m g_{1} M G_{2} M G_{3}$, I003-6c, was crossed to a non-fermenter, I45-I $c$, of genotype $m g_{1} M G_{2} m g_{3}$, and as expected from a hybrid homozygous for $M G_{2}$ and heterozygous for $M G_{3}$, only $2: 2$ segregations were observed in the 2 I asci from this cross (cross I 4, table 4). From another 
hybrid of this same genotype, $m g_{1} M G_{2} M G_{3} / m g_{1} M G_{2} m g_{3}$, I I more asci with only $2: 2$ segregations were obtained (cross I 5 , table 4 ).

To obtain haploids of the genotype $m g_{1} m g_{2} M G_{3}$, I о03-6c was crossed to a non-fermenter strain of the genotype $m g_{1} m g_{2} m g_{3}$, as determined by the zygote tests. The I 2 asci from cross I 6 (table 4) show a distribution of $2: 2,1: 3$, and $0: 4$ segregations close to that expected from two independently segregating complementary genes, i.e. $2: 9:$ I versus $2: 8: 2$. A confirmation of the zygote tests of the segregants from cross i 6 was obtained when a non-fermenter of the predicted genotype $m g_{1} m g_{2} M G_{3}$ was crossed to a fermenter from cross I 4, genotype $m g_{1} M G_{2} M G_{3}$, to give a hybrid which yielded only the expected $2: 2$ segregations in the nine asci analysed (cross I7, table 4).

A cross of two alpha-methyl-glucoside fermenters was made to substantiate the contention that $M G_{1}$ and $M G_{3}$ are polymeric genes. One haploid parent, I $3^{6} 6$ - $7 a$, was from cross 7 where $2: 2$ segregations were obtained for $M G_{1}$ and the complementary gene, $M G_{2}$, was homozygous dominant. Similarly, the other parent, I040-5b, was from cross I5 where $2: 2$ segregations were obtained for $M G_{3}$ and again $M G_{2}$ was homozygous dominant. The distribution of the segregations, $2(4: 0), 9(3: 1)$, and $3(2: 2)$ for the i 4 asci (cross I 8 , table 4 ) is in accordance with the ratios expected for two independently segregating genes which show little or no centromere linkage.

\section{Evidence for the gene $\mathrm{MG}_{4}$}

When crosses were made to a new fermenter strain, haploid I $426 \mathrm{~A}$, received from Dr Lindegren, segregation ratios were observed which indicated that a new gene combination was enabling this haploid to ferment alpha-methyl-glucoside. Haploid I426A was first crossed to a strain of genotype $m g_{1} M G_{2} m g_{3}$, I о 8-4a, previously used as the non-fermenter parent in crosses 6 and 7 . The segregations in ro asci (cross 19 , table 5$)$ are $1(4: 0), 3(3: 1), 3(2: 2)$, and $3(1: 3)$. The genot rpe of the hybrid and therefore I $426 \mathrm{~A}$, with reference to the $M G_{1} M G_{2}$, and $M G_{3}$ loci, can be adduced from the following considerations. As in cross 18 , the $4: 0$ and $3:$ I ratios indicate that two polymeric genes or combinations of genes are heterozygous in this hybrid. However, the combination $M G_{1} M G_{2} M G_{3} / m g_{1} M G_{2} m g_{3}$ is precluded since a hybrid homozygous for $M G_{2}$ would not give I $: 3$ ratios. Thus the occurrence of $\mathrm{I}: 3$ ratios indicates that $M G_{2}$ is not present in $1426 \mathrm{~A}$ and, therefore, that a new gene $M G_{4}$ is responsible for the fermentation of alpha-methyl-glucoside in this haploid. The I : 3 ratios also eliminate the possibility that $M G_{4}$ is alone sufficient for fermentation. Does $M G_{4}$ act in concert with yet another new gene? Or, is $M G_{4}$ equivalent to $M G_{2}$ in requiring either $M G_{1}$ or $M G_{3}$ for alpha-methyl-glucoside fermentation? For example, if $M G_{4}$ and $M G_{2}$ are equivalent, all the above ratios can be accounted for by the genotype $M G_{1} m g_{2} M G_{3} M G_{4} / m g_{1} M G_{2} m g_{3} m g_{4}$ 
which would result in the following distribution of ascus types providing there was no case of linkage involved : $6(4: 0), 72(3: 1), 97(2: 2)$, $28(\mathrm{I}: 3)$, and $\mathrm{I}(\mathrm{o}: 4)$. However, this interpretation was shown to be inadequate when the next cross of $1426 \mathrm{~A}$ with $1018-2 b$, a complete recessive $m g_{1} m g_{2} m g_{3} m g_{4}$, gave 9 asci with these ratios: $3(2: 2)$, I ( $1: 3)$, and $5(0: 4)$. If $M G_{4}$ is equivalent to $M G_{2}$, the situation would be analogous to that in crosses I I and I 2 and a preponderance of $2: 2$ segregations would be expected. The distribution of the segregation ratios requires either (I) that $M G_{1}$ or $M G_{3}$, but not both, is complementary to $M G_{4}$ if ${ }_{1426 \mathrm{~A}}$ is $M G_{1} m g_{2} M G_{3} M G_{4}$, or (2) that neither $M G_{1}$ nor $M G_{3}$ are complementary to $M G_{4}$ and that a fifth gene must be postulated which in combination with $M G_{4}$ will permit fermentation. A further observation favoured the second possibility and provided evidence of the identity of the new gene. The asci from cross 20 (table 5) had 2:2 segregations for maltose fermentation (of the parents, I426A was a fermenter whereas Io $8-2 b$ was not), and each alpha-methyl-glucoside fermenter obtained from this cross was also a maltose fermenter. The simplest interpretation is that the maltose gene segregating in cross 20, identified as $M A_{1}$, is involved in the fermentation of alpha-methyl-glucoside. This interpretation was supported by the results of intra-ascus zygote tests with the four haploids from a $0: 4$ ascus of cross 20 :

$$
\begin{array}{ll}
\operatorname{I028}-9 a(-) \times 1028-9 b(-) \ldots(+) & 1028-9 d(-) \times 1028-9 b(-) \ldots(-) \\
1028-9 a(-) \times 1028-9 c(-) \ldots(-) & 1028-9 d(-) \times 1028-9 c(-) \ldots(+)
\end{array}
$$

Under the hypothesis that 2 genes are needed to enable the haploids of 1028 to ferment alpha-methyl-glucoside, these results indicate that $9 a$ and $g^{c}$ have the same gene and that $9^{b}$ and $9^{d}$ have the other gene. The segregants $9 b$ and $g d$ were maltose fermenters. Since the segregants $9^{a}$ and $9^{c}$ were maltose non-fermenters, the gene they carried was designated as $M G_{4}$.

To confirm the participation of the maltose gene $M A_{1}$ in the gene combination which enabled haploids of 1028 to ferment alpha-methylglucoside, a hybrid predicted to be homozygous for $M G_{4}$ and heterozygous for the complementary gene was obtained by crossing I028-9c with I028-6c, a fermenter of alpha-methyl-glucoside and maltose. It was expected that this hybrid would yield asci with $2: 2$ segregations for both alpha-methyl-glucoside and maltose fermentation, and if the above interpretation is correct, all the maltose fermenters would be alpha-methyl-glucoside fermenters. In the II tetrads that were obtained (cross 2 I, table 5), maltose segregated $2: 2$, but for alphamethyl-glucoside there were $9(2: 2)$, and $2(\mathrm{I}: 3)$ asci. Again every alpha-methyl-glucoside fermenter was also a maltose fermenter. In the 2 asci with $1: 3$ segregations, the haploids which were maltose fermenters but alpha-methyl-glucoside non-fermenters were found to be " petites" or cytochrome-deficient yeasts as described by Ephrussi, Hottinguer, and Chimenes (1949). Among the alpha-methyl-glucoside 
fermenters from this hybrid as well as those from hybrid I028, there were no petites although about 20 per cent. of the segregants from these hybrids were petites. In an experiment to investigate this relationship, a fermenter haploid, I 042-2d, was treated with acriflavine (Ephrussi, Hottinguer, and Tavlitski, I949) to obtain a petite clone, I $042-2 d^{\prime}$. This petite strain was then tested on alpha-methyl-glucoside and found to be a non-fermenter. When, however, this petite clone, I042-2 $d^{\prime}$, and the spontaneous petite segregant, I042-9b, from one of the I : 3 asci were checked by means of zygote tests with a normal strain of genotype $m g_{1} m g_{2} m g_{3} m g_{4} M A_{1}$, the presence of $M G_{4}$ was indicated since the cultures descended from the normal zygotes were capable of fermenting alpha-methyl-glucoside

$$
\text { I } 442-2 d^{\prime}(-) \times \operatorname{I} 42-\mathrm{I} d(-) \ldots(+) \quad \operatorname{IO} 42-9 b(-) \times \operatorname{I} 42-\mathrm{I} d(\mathrm{I}) \ldots(+)
$$

TABLE 5

Segregations for alpha-methyl-glucoside fermentation in asci from hybrids involving $1426 \mathrm{~A}$ and its descendants

\begin{tabular}{|c|c|c|c|c|c|c|c|}
\hline \multirow{2}{*}{ Cross } & \multirow{2}{*}{ Parents and phenotypes } & \multirow{2}{*}{$\begin{array}{l}\text { Hybrid and } \\
\text { phenotype }\end{array}$} & \multicolumn{5}{|c|}{ Number of asci segregating as } \\
\hline & & & $4+: 0-$ & $3+: 1-$ & $2+: 2-$ & $1+: 3-$ & $0+: 4-^{*}$ \\
\hline 19 & $1426 \mathrm{~A}(+) \times 1018-4 a(-)$. & $1027(+)$ & I & 3 & 3 & 3 & 0 \\
\hline 20 & $1426 \mathrm{~A}(+) \times 1018-2 b(-)$. & $1028(+)$ & 0 & o & 3 & $\mathrm{I}$ & 5 \\
\hline 21 & $1028-6 b(+) \times 1028-9 c(-)$ & $1042(+)$ & 0 & 0 & 9 & 2 & 0 \\
\hline 22 & $104^{2-2 d}(+) \times 14^{2-1 d}(-)$ & $1044(+)$ & o & o & 4 & I & 0 \\
\hline 23 & $1044^{-1} c(+) \times 13^{36-4 c}(-)$ & $1057(+)$ & o & o & 7 & $\mathrm{o}$ & $\mathrm{o}$ \\
\hline
\end{tabular}

* Fermenters $(+)$ : non-fermenters $(-)$.

From these observations, it was concluded that strains of genotype $m g_{1} m g_{2} m g_{3} M G_{4} M A_{1}$ are unable to ferment alpha-methyl-glucoside if they are petites. It should be noted here that petite clones of the other fermenter genotypes are capable of fermenting alpha-methylglucoside although there is a delay of usually 3 or 4 days in the expression of the positive test.

To demonstrate the segregation of $M G_{4}$, crosses were made to give hybrids homozygous for $M A_{1}$ and heterozygous for $M G_{4}$. Of the I 2 tetrads from crosses 22 and 23 (table 5 ) there were I I in which there occurred the expected $2: 2$ segregation for the fermentation of alpha-methyl-glucoside. Again, in the $1: 3$ ascus from cross 22, one of the non-fermenters was a petite.

The presence of $M G_{3}$ in $\mathrm{I}_{42} 6 \mathrm{~A}$ was established in the following manner. Zygote tests with the non-fermenters from a $2: 2$ ascus of I028 indicated that one of the haploids carried a gene complementary to $M G_{2}$. This haploid, I028-2d, was then crossed to a strain of genotype $m g_{1} M G_{2} m g_{3} m g_{4}$ and from this cross a fermenter segregant with the gene combination $M G_{?} M G_{2}$ was used in the test for allelism. The gene $M G_{\text {? }}$ was identified as $M G_{3}$ when the allelism tests with 
ro4o-7a, genotype $m g_{1} M G_{2} M G_{3} m g_{4}$ gave only $4: 0$ asci (cross 25, table 6).

\section{Evidence for an irregular segregation of $\mathrm{MG}_{2}$}

An unexpected I : 3 segregation was observed in one of the $I_{4}$ asci from cross 26 (table 6), which had 1028-2d as the non-fermenter parent. The above tests have established the genotype of 1028-2d as $m g_{1} m g_{2} M G_{3} m g_{4}$. Since the genotype of the fermenter parent, I037-2c, was $m g_{1} M G_{2} M G_{3} m g_{4}$ (see cross I 7, table 4), only $2: 2$ segregations for the gene $M G_{2}$ were expected. The $1: 3$ ratio in the aberrant ascus could be due to a mutation affecting either $M G_{2}$ or

TABLE 6

Segregations for alpha-methyl-glucoside fermentation in asci from hybrids of the following genotypes: $\mathrm{mg}_{1} \mathrm{mg}_{2} \mathrm{MG}_{3} \mathrm{mg}_{4} / \mathrm{mg}_{1} \mathrm{MG}_{2} \mathrm{mg}_{3} \mathrm{mg}_{4}$ in cross $24, \mathrm{mg}_{1} \mathrm{MG}_{2} \mathrm{MG}_{3}$ $\mathrm{mg}_{4} / \mathrm{mg}_{1} \mathrm{MG}_{2} \mathrm{MG}_{3} \mathrm{mg}_{4}$ in cross 25, $\mathrm{mg}_{2} \mathrm{MG}_{2} \mathrm{MG}_{3} \mathrm{mg}_{4} / \mathrm{mg}_{1} \mathrm{mg}_{2} \mathrm{MG}_{3} \mathrm{mg}_{4}$ in cross 26

\begin{tabular}{|c|c|c|c|c|c|c|c|}
\hline \multirow{2}{*}{ Cross } & \multirow{2}{*}{ Parents and phenotypes } & \multirow{2}{*}{$\begin{array}{l}\text { Hybrid and } \\
\text { phenotype }\end{array}$} & \multicolumn{5}{|c|}{ Number of asci segregating as } \\
\hline & & & $4 \div: 0-$ & $3+: 1-$ & $2+: 2-$ & $1+: 3-$ & $0+: 4-*$ \\
\hline 24 & $1028-2 d(-) \times 1093-2 c(-)$ & I $124(+)$ & 0 & 0 & 2 & 0 & 1 \\
\hline 25 & I I $24-3 d(+) \times 1040-7 a(+)$ & I $130(+)$ & I 3 & 0 & 0 & o & 0 \\
\hline 26 & $1037-2 c(+) \times 1028-2 d(-)$ & $1045(t)$ & o & 0 & I3 & I & 0 \\
\hline
\end{tabular}

* Fermenters $(+)$ : non-fermenters $(-)$.

$M G_{3}$. To investigate these possibilities, zygote tests were made with the negative haploids from this ascus :

$$
\begin{aligned}
& \operatorname{I0} 45-9 a(-) \times 1040-6 a(-) \ldots(+) \quad \operatorname{I0} 45-9 a(-) \times 1037-9 a(-) \ldots(-) \\
& \text { I0 } 45-9 b(-) \times 1040-6 c(-) \ldots(+) \quad \text { 1045-9b(-) } \times 1037-9 d(-) \ldots(--) \\
& \operatorname{I0} 45-9 c(-) \times \operatorname{I0} 40-6 a(-) \ldots(+) \quad \text { I045-9c (-) } \times \text { I037-9a (-)...(-) }
\end{aligned}
$$

The zygote tests made with the $m g_{1} M G_{2} m g_{3}$ test strains, Io40-6a and 1040-6c, were positive for each of the three haploids. Those made with the $m g_{1} m g_{2} M G_{3}$ test strains, I037-9 $a$ and I037-9d, were negative. From these results, it can be concluded that the irregular segregation in this ascus was due to a mutation at the $M G_{2}$ locus.

Irregular segregations were also encountered for some of the other genes heterozygous in the foregoing hybrids. The genes for galactose $\left(G_{2}\right)$ and melibiose fermentation, histidine, tryptophane $\left(T R_{1}\right)$, and methionine independence each had a single $3:$ I segregation. There were two asci with $1: 3$ segregations for uracil independence, and 3 asci with $4: 0,3: 1$, and $1: 3$ segregations for sucrose fermentation.

There was no significant evidence of linkage between any of the alpha-methyl-glucoside genes and any of the other genes segregating in these crosses : a/ $\alpha$ mating type ; $G_{1}$ and $G_{2}, M E L, S U_{1}$, and $M A_{1}$, galactose, melibiose, sucrose, and maltose fermentation respectively ; $t r_{1}$ and $t r_{2}, h i_{1}, u r_{1}$, and $m e_{1}$, tryptophane, histidine, uracil, and 
methionine dependence respectively. The centromere linkage data were nor extensive enough to indicate significant centromere linkage for any of the alpha-methyl-glucoside genes.

\section{DISCUSSION}

It is possible to explain satisfactorily the segregations for alphamethyl-glucoside fermentation encountered in some Saccharomyces hybrids on the basis of 5 interacting genes, designated $M G_{1}, M G_{2}$, $M G_{3}, M G_{4}$, and $M A_{1}$. The following combinations of dominant genes confer the capacity to ferment alpha-methyl-glucoside : $M G_{1} M G_{2}, M G_{2} M G_{3}$, and $M G_{4} M A_{1}$. The segregation ratios expected for a number of the possible heterozygous combinations have been given in the preceding sections. For a cross which gives a hybrid heterozygous for all 5 genes, $M G_{1} M G_{2} M G_{3} M G_{4} M A_{1} /$ $m g_{1} m g_{2} m g_{3} m g_{4} m a_{1}$, the following distribution of segregation ratios is expected if the genes segregate independently and show no centromere linkage : I9 (4:0), 352 (3: I), 703 (2:2), $216(\mathrm{I}: 3)$, and $6(0: 4)$.

The need for the presence of two interacting genes to enable a yeast strain to ferment a carbohydrate is not unique to the fermentation of alpha-methyl-glucoside. The fermentation of dextrin or starch by Saccharomyces diastaticus is also under the control of 2 genes, one controlling the splitting of the polysaccharide to maltose and the other controlling the fermentation of maltose (Gilliland, 1953). A more analogous situation is found for the fermentation of galactose where the presence of 2 dominant genes, $G_{1}$ and $G_{2}$, is essential for rapid fermentation (Leupold and Hottinguer, I954; and Douglas and Condie, 1954). As a working hypothesis, the role of genes $G_{1}$ and $G_{2}$ was postulated by the latter investigators to be that $G_{1}$ controls the formation of an enzyme involved in the conversion of galactose to glucose-5-phosphate, and $G_{2}$ controls a mechanism for transporting galactose into the cell. As yet, the roles of the alpha-methyl-glucosire genes have not been investigated.

The presence of the gene combination $M G_{4} M A_{1}$ also enables a yeast strain to ferment sucrose although at a noticeably lower rate than when one of the specific sucrose genes is present: i.e. $4^{8}$ to 72 hours are required for a full gas trap in a Durham fermentation tube with the $M G_{4} M A_{1}$ combination as compared to 16 to 24 hours with any one of the specific sucrose genes thus far isolated. It was postulated by Gilliland (1949) and demonstrated by Winge and Roberts (1952) that a maltose gene in their stocks, designated $M_{1}$, could enable a yeast strain to ferment sucrose slowly. Winge and Roberts (1955) established that this gene is allelic with the $M A_{1}$ of our stocks. However, in our stocks, strains with the gene $M A_{1}$ alone do not ferment sucrose at a detectable rate when tested in Durham tubes containing a medium consisting of I per cent. peptone, I per cent. yeast extract, and 2 per cent. sucrose. 
The maltose gene and the 4 alpha-methyl-glucoside genes were isolated from stocks derived from 6 different parental strains. Two of the parental strains were obtained from Dr C. C. Lindegren and 4 were from stocks descended from strains originating in his laboratory. The source of these genes is of importance since Lindegren (1953) also has encountered irregular segregations for alpha-methyl-glucoside fermentation but has interpreted the deviations from a $2: 2$ ratio as cases of "gene conversion". The irregularities in families with only a small proportion of anomalous asci, such as families VII and XI with I $(4: 0), 20(2: 2)$, and $2(3: 1), 30(2: 2)$ segregations respectively (table I, p. 627, Lindegren, 1953), might reasonably be attributed to gene conversion. However, some of the cases that are cited may be explained on the basis of multiple genes. For example, the distribution of the segregation ratios in family XV (table I, p. 627, Lindegren, 1953) with I $(3: 1), 20(2: 2)$, I 8 (I:3), and I $(0: 4)$ asci would be expected, with the exception of the $3: 1$ ascus, from a hybrid heterozygous for the 3 genes $M G_{1}, M G_{2}$, and $M G_{3}$. In another case, the irregular segregations may be due to the occurrence of petite clones amongst segregants with the gene combination $M G_{4} M A_{1}$. In family XXVIII (table I, p. 627, fig. I, p. 628 Lindegren, I953), 9 asci out of 13 gave $2: 2$ segregations for both maltose and alphamethyl-glucoside and in each case, the alpha-methyl-glucoside fermenters were maltose fermenters. In the remaining asci, there were I $(\mathrm{I}: 3)$ and $3(4: 0)$ segregations for alpha-methyl-glucoside fermentation. The fermenter parent in this cross, 1426 , was shown above to be of genotype $m g_{1} m g_{2} M G_{3} M G_{4} M A_{1}$. If the non-fermenter parent, I 2736, is of genotype $m g_{1} m g_{2} m g_{3} M G_{4} m a_{1}$, the observations of Lindegren can be accounted for by the occurrence of petite clones in the asci with the aberrant ratios. It has been noted in crosses with I 426 (crosses 19 and 20, table 5) that about 20 per cent. of the spore cultures are petite and frequently more than one petite spore culture arose from the same ascus.

The 9 asci where maltose and alpha-methyl-glucoside fermentation segregate together are cited by Lindegren as evidence supporting the location of $M A$ and $M G$ on the same chromosome. In the other families that he considers, there is no evidence of linkage for these genes from his summary of the data : 26 parental ditype, 33 nonparental ditype, and 99 tetratype asci. To account for this inconsistency of the data, a crossover suppressor is postulated for family XXVIII. It seems more probable, however, that different alphamethyl-glucoside genes are being compared. These genes need not necessarily be $M G_{1}, M G_{2}, M G_{3}$, or $M G_{4}$ since it is highly probable that if in a sample of 6 strains there are found 5 different genes involved in alpha-methyl-glucoside fermentation, there exist other genes controlling this ability. Nevertheless, the irregular segregations in some of the families in the pedigree he presents may be explained on the basis of interacting genes, and this possibility must be kept in 
mind when considering his data on alpha-methyl-glucoside fermentation as evidence pertaining to gene conversion.

\section{SUMMARY}

The distribution of the $2: 2$, I : 3 , and $0: 4$ segregations for alpha-methyl-glucoside fermentation in the four-spored asci of Saccharomyces hybrids led to the postulation that 3 genes, $M G_{1}$, $M G_{2}$, and $M G_{3}$, are involved. A yeast with the dominant gene $M G_{2}$ and either dominant gene $M G_{1}$ or $M G_{3}$ is able to ferment alphamethyl-glucoside. An additional gene combination enabling fermentation, $M G_{4} M A_{1}$, was discovered when a cross which yielded $4: 0$, $3:$ I, $2: 2$, and $\mathrm{I}: 3$ ratios was investigated. Crosses were made which resulted in the segregation of a single gene at a time, and $2: 2$ ratios were obtained except for 4 anomalous $\mathrm{I}: 3$ asci. Three of the anomalous asci involved the gene combination $M G_{4} M A_{1}$ and can be explained by the occurrence of petite spore clones from these asci since it was demonstrated that petite strains with this gene combination could not ferment alpha-methyl-glucoside. The irregular segregation in the fourth ascus is attributed to the mutation of the gene $M G_{2}$.

Acknowledgments. - The author wishes to thank Drs Howard C. Douglas and Herschel Roman for their advice and interest in this investigation. $\mathrm{He}$ is also indebted to Dr Carl C. Lindegren who made available the parental strains from which some of the hybrids used in this study were developed. This investigation received support from the Biological and Medical Research Fund of the State of Washington, and the National Institutes of Health, Public Health Service, Grant No. E-328.

\section{REFERENCES}

CHEN, s. 1950. Sur une nouvelle technique de croisement des levures. Compt. Rend., 230, $1897-1899$.

DOUglas, H. C., AND CONDIE, F. 1954. The genetic contrc ${ }^{1}$ of galactose utilisation in Saccharomyces. F. Bact., 68, 662-670.

EPHRUSSI, B., hotTinguer, H., AND chimenes, A. M. 1949. Action de l'acriflavine sur les levures. I. La mutation " petite colonie". Ann. Inst. Past., 76, 351-367.

ephrussi, B., hottinguer, H., AND tAVlitski, J. 1949. Action de l'acriflavine sur les levures. II. Étude génétique du mutant "petite colonie". Ann. Inst. Past., 76, 419-450.

GILLILAND, R. B. 1949. A yeast hybrid heterozygous in four fermentation characters. Compt. Rend. Lab. Carlsberg, Ser. Physiol., 24, 347-356.

GILI.ILAND, R. B. 1953. The genetics of super-attenuation. European Brewery Convention, Proceedings 1953, pp. $121-134$.

HAWTHORNE, D. C. 1955. The use of linear asci for chromosome mapping in Saccharomyces. Genetics, 40, 511-518.

HAWTHORNE, D. C. 1956. The genetics of galactose fermentation in Saccharomyces hybrids. Compt. Rend. Lab. Carlsberg, Ser. Physiol., 26, 149-16o.

LeUpold, U., AND hottinguer, H. 1954. Some data on segregation in Saccharomyces. Heredity, 8, 243-258.

L.INDEGREn, c. c. 1949. The Teast Cell, Its Genetics and Cytology. Educational Publishers Inc., St Louis. 
LINDEGREN, C. C. 1953. Gene conversion in Saccharomyces. 7. Genet., 51, 625-637. LINDEGREN, C. C., AND LINDEGREN, G. 1943. A new method for hybridising yeast. Proc. Nat. Acad. Sci., 29, 306-308.

LINDEGREN, C. C., AND LINDEGREN, G. 1956. Effect of the local chromosomal environment upon the genotype. Nature, $178,796-797$.

POMPER, S., AND BURKHOLDER, P. R. I949. Studies of the biochemical genetics of yeast. Proc. Nat. Acad. Sci., 35, 456-464.

ROMAN, H., HAWTHORNe, D. C., AND DOUglas, H. C. I95I. Polyploidy in yeast and its bearing on the occurrence of irregular genetic ratios. Proc. Nat. Acad. Sci., 37, 79-84.

RCMAN, H., AND SANDS, S. M. 1953. Heterogeneity of clones of Saccharomyces derived from haploid ascospores. Proc. Nat. Acad. Sci., 39, I 7 I-1 79 .

WINGE, Ø., AND ROBERTS, C. 1952. The relation between the polymeric genes for maltose, raffinose, and sucrose fermentation in yeast. Compt. Rend. Lab. Carlsberg, Ser. Physiol., 25, I 4 I-I 7 I.

WINGE, ø., AND ROBERTS, C. I954. Causes of deviations from $2: 2$ segregations in the tetrads of monohybrid yeasts. Compt. Rend. Lab. Carlsberg, Ser. Physiol., $25,285-329$.

WINGE, Ø., AND ROBERTS, C. I955. Identification of the maltose genes in some American haploid and European diploid yeasts. Compt. Rend. Lab. Carlsberg, Ser. Physiol., 25, 33 1-340. 